Article

\title{
Enzymatic Synthesis of Extremely Pure Triacylglycerols Enriched in Conjugated Linoleic Acids
}

\author{
Yu Cao ${ }^{1}$, Weifei Wang ${ }^{2}$, Yang $\mathrm{Xu}^{2}$, Bo Yang ${ }^{1, *}$ and Yonghua Wang ${ }^{2, *}$ \\ 1 School of Bioscience and Bioengineering, South China University of Technology, \\ Guangzhou 510006, China \\ 2 College of Light Industry and Food Sciences, South China University of Technology, \\ Guangzhou 510640, China
}

* Author to whom correspondence should be addressed; E-Mails: yonghw@scut.edu.cn (Y.W.), yangbo@scut.edu.cn (B.Y.); Tel./Fax: +86-20-8711-3842 (Y.W.);

Tel./Fax: +86-20-3938-0696 (B.Y.).

Received: 10 May 2013; in revised form: 5 August 2013 / Accepted: 12 August 2013 /

Published: 13 August 2013

\begin{abstract}
This work was objectively targeted to synthesize extremely pure triacylglycerols (TAG) enriched in conjugated linoleic acids (CLAs) for medical and dietetic purposes. Extremely pure CLA-enriched TAG was successfully synthesized by using the multi-step process: TAG was primarily synthesized by lipase-catalyzed esterification of CLA and glycerol and then the lower glycerides [monoacylglycerol (MAG) and diacylglycerol (DAG)] in the esterification mixtures was hydrolyzed to free fatty acids (FFAs) by a monoand di-acylglycerol lipase (lipase SMG1), finally, the FFAs were further separated from TAG by low temperature $\left(150^{\circ} \mathrm{C}\right)$ molecular distillation. The operation parameters for the lipase SMG1-catalyzed hydrolysis were optimized using response surface methodology based on the central composite rotatable design (CCRD). The operation parameters included water content, $\mathrm{pH}$ and reaction temperature and all of these three parameters showed significant effects on the hydrolysis of lower glycerides. The optimal conditions were obtained with a water content of $66.4 \%$ (w/w, with respect to oil mass), $\mathrm{pH}$ at 5.7 and $1 \mathrm{~h}$ of reaction time at $19.6{ }^{\circ} \mathrm{C}$. Under these conditions, the content of lower glycerides in the reaction mixture decreased from $45.2 \%$ to $0.3 \%$ and the purity of CLA-enriched TAG reached $99.7 \%$. Further purification of TAG was accomplished by molecular distillation and the final CLA-enriched TAG product yielded $99.8 \%$ of TAG. These extremely pure CLA-enriched TAG would be used for in vivo studies in animals and humans in order to get specific information concerning CLA metabolism.
\end{abstract}


Keywords: conjugated linoleic acid; mono- and di-acylglycerol lipase; hydrolysis; triacylglycerols

\section{Introduction}

Conjugated linoleic acid (CLA), referring to a heterogeneous group of geometrical and positional conjugated isomers of linoleic acid (LA, 18:2), has received increasing attention because of its demonstrated biological properties, including cancer inhibition [1-4], blood cholesterol lowering [5], diabetes controlling and weight loss effects [6,7]. Most of these studies, however, were carried out with CLA as free fatty acid (FFA) [4-7] and only a few studies have used CLA in the form of triacylglycerols (TAG) $[8,9]$. This is mainly because the CLA as FFA was the only material readily available, while CLA in TAG form is hard to be obtained because of its low purity, with lower glyceride [monoacylglycerol (MAG) and diacylglycerol (DAG)] contaminants. Since the nutritional profile and rheological behaviors of lipids depends on both their fatty acid composition and acylglycerol composition [10], the presence of these lower glycerides will impede the further understanding of nutraceutical effects of CLA in TAG form. Thus, in order to get specific information concerning CLA metabolism, it is necessary to synthesize highly pure TAGs enriched in CLA.

CLA-enriched TAG can be synthesized chemically or enzymatically through esterification or transesterification processes [11-13]. Compared with chemical methods, lipase-catalysed esterification provides an alternative process due to its mild performance conditions, which prevents CLA from being destroyed. Nevertheless, the purity of TAG products produced through esterification is always less than desirable because of the presence of lower glycerides. High temperature molecular distillation $\left(220-250{ }^{\circ} \mathrm{C}\right)$ is a universally used technique to purify TAG products containing MAG and DAG. However, it is not suitable for the purification of CLA-enriched TAG, because it would lead to temperature-induced isomeration and thus the formation of unwanted CLA isomers. Thus, to attempt the purification of CLA-enriched TAG would be a challenging task.

In this paper, we aim to produce extremely pure CLA-enriched TAGs by a multi-step process. Firstly, the CLA-enriched TAG was synthesized by lipase-catalyzed esterification of CLA and glycerol, and then the lower glycerides (e.g., MAG and DAG) in the esterification mixtures were further hydrolyzed to FFA by lipase SMG1 (a novel mono- and di-acylglycerol lipase) and the hydrolysis process was optimized by the response surface methodology (RSM). Finally, the CLA-enriched TAG was easily separated by molecular distillation at a lower temperature $\left(150^{\circ} \mathrm{C}\right)$. This method enables the synthesis of extremely pure CLA-enriched TAG for medical and dietetic research purposes.

\section{Results and Discussion}

\subsection{Lipase-Catalyzed Synthesis of CLA-Enriched TAG}

CLA-enriched TAG was produced by Novozym 435-catalyzed esterification of glycerol and CLA under vacuum. The reaction was performed under the condition of a CLA/glycerol molar ratio of 3:1, an enzyme load of $1 \%\left(\mathrm{w} / \mathrm{w}\right.$, with respect to total reactants), at $60{ }^{\circ} \mathrm{C}$ and $0.1 \mathrm{kPa}$ for $6 \mathrm{~h}$. The results are 
shown in Figure 1. The content of TAG rose gradually to $40.24 \%$ after 6 h of reaction, while the DAG content increased dramatically at the first $2 \mathrm{~h}$ but then remained stable at around $40 \%$. The content of MAG, however, increased sharply at first $1 \mathrm{~h}$ and then decreased slowly to around $1 \%$ at the end. After a total reaction time of $6 \mathrm{~h}$, esterification product contained 40.24\% TAG, $14.56 \% \mathrm{FFA}, 44.14 \% \mathrm{DAG}$ and $1.06 \% \mathrm{MAG}$ were achieved. The FA composition of the TAG fraction in the esterification product was analyzed and the CLA content in the TAG fraction reached to $80.22 \%$.

Figure 1. Novo 435 catalyzed esterification of CLA and glycerol. Reaction conditions were as follows: CLA/glycerol molar ratio, 3:1; enzyme loading, $1 \%(\mathrm{w} / \mathrm{w}$, with respect to total reactants); temperature, $60{ }^{\circ} \mathrm{C}$; pressure, $0.1 \mathrm{kPa}$; reaction time, $6 \mathrm{~h}$.

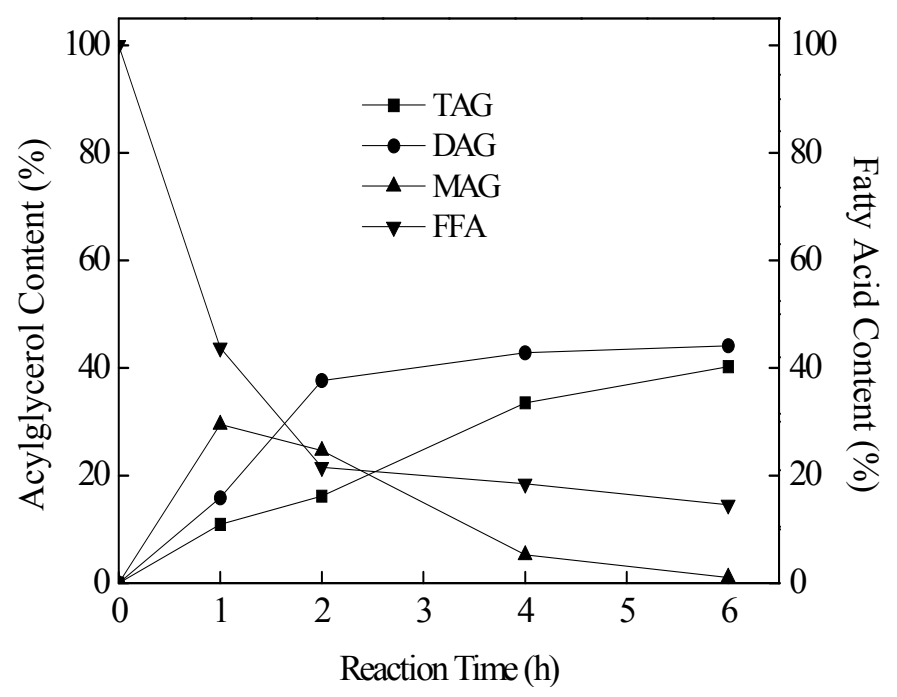

\subsection{Lipase SMG1-Catalyzed Hydrolysis of Lower Glycerides in TAG Products}

In order to obtain highly pure CLA-enriched TAG products, the above reaction mixture were further purified, and the lipase SMG1 was employed to hydrolyze lower glycerides (MAGs and DAGs) in the reaction mixture. The lipase SMG1-catalyzed hydrolysis process was optimized by response surface methodology.

\subsubsection{Model Analysis to Estimate the Coefficients}

The CCRD was adopted in this study to identify the importance of the variables (water content, $\mathrm{pH}$ and reaction temperature) in the hydrolysis reaction. The experimental design matrix and the corresponding results are shown in Table 1. By applying regression analysis on the experimental data, the quadratic regression equations model is as follows (Equation 1), representing the TAG purity expressed as a function of variables:

$$
\begin{gathered}
\text { Purity of TAG }=99.53+2.85 \mathrm{X}_{1}+0.72 \mathrm{X}_{2}-2.35 \mathrm{X}_{3}+1.50 \mathrm{X}_{1} \mathrm{X}_{2}+1.40 \mathrm{X}_{1} \mathrm{X}_{3}-1.20 \mathrm{X}_{2} \mathrm{X}_{3}-1.99 \mathrm{X}_{1}^{2}- \\
4.80 \mathrm{X}_{2}^{2}-1.76 \mathrm{X}_{3}^{2}
\end{gathered}
$$

where $\mathrm{X}_{1}, \mathrm{X}_{2}$, and $\mathrm{X}_{3}$ are the water content, $\mathrm{pH}$ and reaction temperature, respectively. 
Table 1. Experimental design and results of CCRD optimization experiment ${ }^{\mathrm{a}}$.

\begin{tabular}{|c|c|c|c|c|c|}
\hline \multirow{2}{*}{ Trials } & \multirow{2}{*}{$X_{1}$} & \multirow{2}{*}{$X_{2}$} & \multirow{2}{*}{$X_{3}$} & \multicolumn{2}{|c|}{ Purity of TAG (\%) } \\
\hline & & & & Observed & Predicted \\
\hline 1 & $-1(30)$ & $-1(5)$ & $-1(20)$ & $91.5 \pm 0.14$ & 91.47 \\
\hline 2 & $1(90)$ & $-1(5)$ & $-1(20)$ & $91.3 \pm 0.17$ & 91.37 \\
\hline 3 & $-1(30)$ & $1(6)$ & $-1(20)$ & $92.3 \pm 0.11$ & 92.31 \\
\hline 4 & $1(90)$ & $1(6)$ & $-1(20)$ & $98.3 \pm 0.13$ & 98.21 \\
\hline 5 & $-1(30)$ & $-1(5)$ & $1(30)$ & $86.3 \pm 0.10$ & 86.37 \\
\hline 6 & $1(90)$ & $-1(5)$ & $1(30)$ & $91.9 \pm 0.16$ & 91.87 \\
\hline 7 & $-1(30)$ & $1(6)$ & $1(30)$ & $82.5 \pm 0.17$ & 82.41 \\
\hline 8 & $1(90)$ & $1(6)$ & $1(30)$ & $93.9 \pm 0.12$ & 93.92 \\
\hline 9 & $-1.68(9.5)$ & $0(5.5)$ & $0(25)$ & $89.1 \pm 0.09$ & 89.12 \\
\hline 10 & $1.68(110.4)$ & $0(5.5)$ & $0(25)$ & $98.7 \pm 0.11$ & 98.71 \\
\hline 11 & $0(60)$ & $-1.68(4.6)$ & $0(25)$ & $84.8 \pm 0.14$ & 84.75 \\
\hline 12 & $0(60)$ & $1.68(6.3)$ & $0(25)$ & $87.1 \pm 0.14$ & 87.18 \\
\hline 13 & $0(60)$ & $0(5.5)$ & $-1.68(16.6)$ & $98.5 \pm 0.11$ & 98.51 \\
\hline 14 & $0(60)$ & $0(5.5)$ & $1.68(33.4)$ & $90.6 \pm 0.13$ & 90.61 \\
\hline 15 & $0(60)$ & $0(5.5)$ & $0(25)$ & $99.5 \pm 0.08$ & 99.53 \\
\hline 16 & $0(60)$ & $0(5.5)$ & $0(25)$ & $99.5 \pm 0.11$ & 99.53 \\
\hline 17 & $0(60)$ & $0(5.5)$ & $0(25)$ & $99.7 \pm 0.12$ & 99.53 \\
\hline 18 & $0(60)$ & $0(5.5)$ & $0(25)$ & $99.4 \pm 0.10$ & 99.53 \\
\hline 19 & $0(60)$ & $0(5.5)$ & $0(25)$ & $99.5 \pm 0.13$ & 99.53 \\
\hline 20 & $0(60)$ & $0(5.5)$ & $0(25)$ & $99.6 \pm 0.12$ & 99.53 \\
\hline
\end{tabular}

${ }^{\mathrm{a}} X_{1}$, water content (w/w, with respect to total oil mass); $X_{2}, \mathrm{pH}$ value; $X_{3}$, reaction temperature $\left({ }^{\circ} \mathrm{C}\right)$.

Statistical experimental design techniques have been proved to be very useful tools for process optimization as they can not only complete optimization but also provide statistical models that assist in understanding the interaction of different variables [14]. The ANOVA was performed for the response surface quadratic model and the results are shown in Table 2. From the P-values of terms in Table 2, it can be seen that all of the terms, including the linear and square terms of water content, $\mathrm{pH}$, temperature, and the interaction of the water content and $\mathrm{pH}$, interaction of water content and reaction temperature and interaction of reaction temperature and $\mathrm{pH}$, were highly significant on the TAG purity $(p<0.05)$. The mathematical model was very reliable, with an R2 value of 0.9999 . The closer R2 is to 1 , the better the model fits the experimental data, and the less the difference between the predicted and the observed values. The low $\mathrm{CV}$ value of $0.10 \%$ indicated the great degree of precision with which the treatments were compared. The computed $\mathrm{F}$ value of 7728.11 was much greater than the $F_{(9,10)}$ value in statistical tables at a $1 \%$ level. It reflected the significance of the model.

\subsubsection{Main Effects and Interaction between Parameters}

Since all three factors including water content, $\mathrm{pH}$ and reaction temperature affect the hydrolysis of lower glycerides significantly, the effect of these parameters on TAG purity was elucidated in detail and the results are shown in Figure 2. Effect of water content on the TAG purity increased dramatically with the water content increasing from $30 \%$ to $60 \%$ and thereafter, further increase in water content did not significantly improve the TAG purity (Figure 2a). It might result from the dilution effect on biocatalyst 
caused by excessive water [15]. The $\mathrm{pH}$ plays an important role in the lipase catalyzed hydrolysis of lower glycerides and thus significantly affected the TAG purity. As shown in Figure 2b, the TAG purity in the reaction products increased dramatically when the $\mathrm{pH}$ increased from 5 to 5.5 while an obvious decrease of TAG purity was found when $\mathrm{pH}$ was further increased to 6.0. Reaction temperature also has a significant effect on the lipase activity as well as the lipase catalyzed hydrolysis. As presented in Figure $2 \mathrm{c}$, TAG purity decreased slightly with the temperature increasing from 20 to $25^{\circ} \mathrm{C}$ while when the temperature further increased, the TAG purity decreased dramatically due to the denaturation of protein by the high temperature. In our previous study, the optimum temperature for maximum lipase activity of lipase SMG1 is between 25 and $30^{\circ} \mathrm{C}$ [16], and the highest TAG purity was obtained at $20{ }^{\circ} \mathrm{C}$ which was consistent with the former results.

Table 2. Model-fitting results and analysis of variance for the TAG purity ${ }^{\mathrm{a}}$.

\begin{tabular}{|c|c|c|c|c|}
\hline Source & Degree of freedom & Mean square & $F$ value & Prob $>F$ \\
\hline Model & 9 & 69.21 & 7728.11 & $<0.0001$ \\
\hline $\mathrm{X}_{1}$ & 1 & 111.06 & 12400.74 & $<0.0001$ \\
\hline $\mathrm{X}_{2}$ & 1 & 7.13 & 796.18 & $<0.0001$ \\
\hline $\mathrm{X}_{3}$ & 1 & 75.38 & 8417.34 & $<0.0001$ \\
\hline $\mathrm{X}_{1} \mathrm{X}_{2}$ & 1 & 18.00 & 2009.85 & $<0.0001$ \\
\hline $\mathrm{X}_{1} \mathrm{X}_{3}$ & 1 & 15.68 & 1750.80 & $<0.0001$ \\
\hline $\mathrm{X}_{2} \mathrm{X}_{3}$ & 1 & 11.52 & 1286.30 & $<0.0001$ \\
\hline $\mathrm{X}_{1}^{2}$ & 1 & 56.89 & 6352.52 & $<0.0001$ \\
\hline $\mathrm{X}_{2}^{2}$ & 1 & 331.71 & 37038.25 & $<0.0001$ \\
\hline $\mathrm{X}_{3}^{2}$ & 1 & 44.49 & 4968.01 & $<0.0001$ \\
\hline Residual & 10 & $8.956 \mathrm{E}-003$ & & \\
\hline Lack of Fit & 5 & $7.245 \mathrm{E}-003$ & 0.68 & 0.6592 \\
\hline Pure Error & 5 & 0.011 & & \\
\hline
\end{tabular}

Figure 2. Main effect plot showing the effect of water content (a), $\mathrm{pH}(\mathbf{b})$ and temperature $\left({ }^{\circ} \mathrm{C}\right)$ on TAG purity.

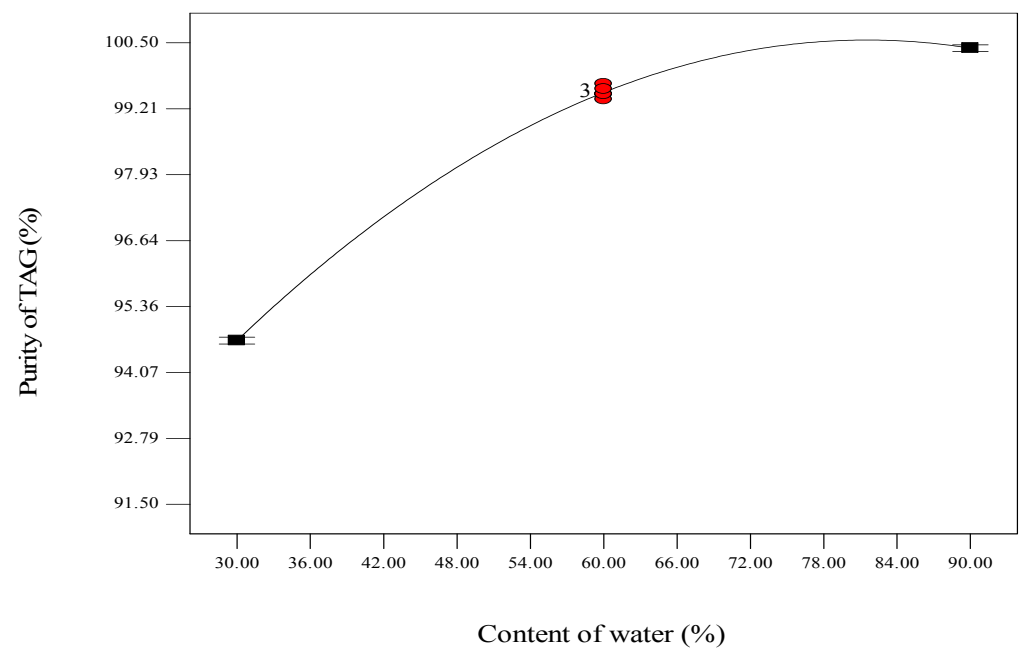

(a) 
Figure 2. Cont.

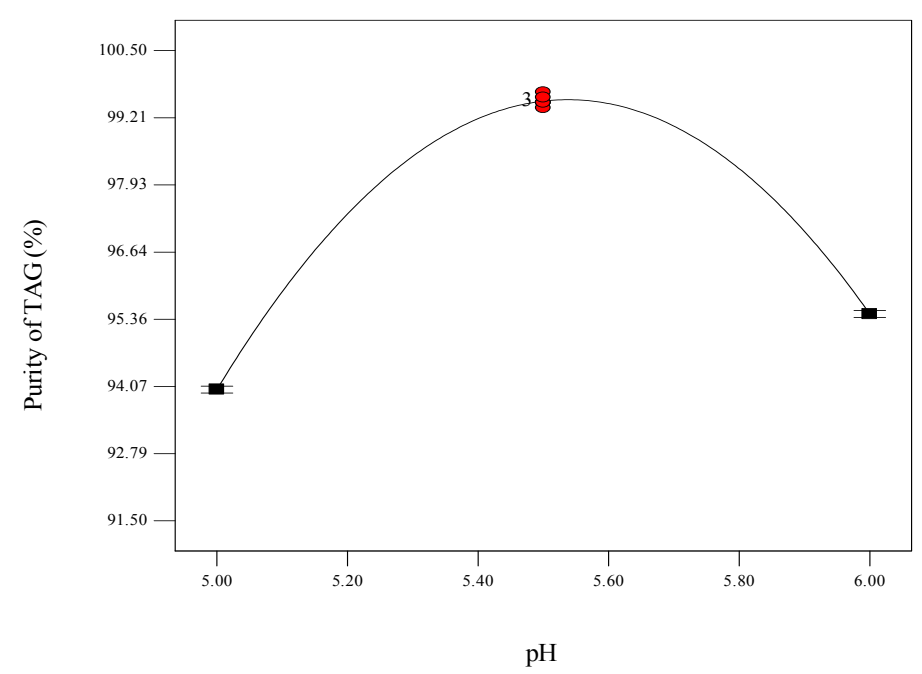

(b)

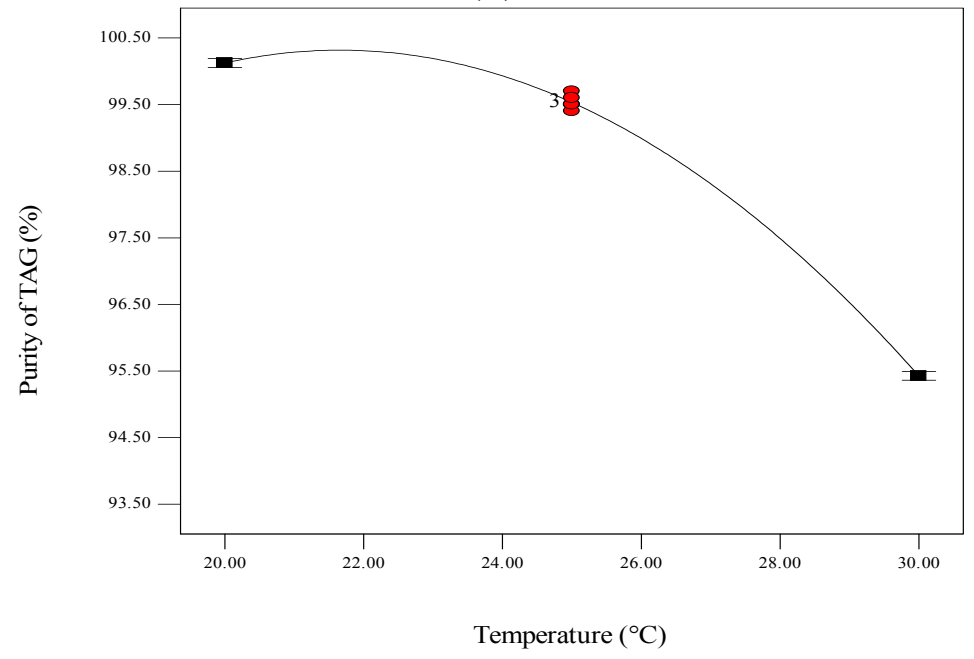

(c)

To investigate the interaction between three factors on TAG purity, the response surface curves and the contour curves for the water content, $\mathrm{pH}$, and reaction temperature are shown in Figures 3-5. The response surface representing TAG purity was a function of two factors with another variable fixed at an constant level. The optimal levels and interaction between two factors were clearly revealed. Based on the response surface curve which was constructed for center level of temperature and water content (Figure 3), it is observed that the TAG purity increased with increasing the water content and decreasing the reaction temperature and higher water content and lower reaction temperature can improve the TAG purity. The interaction between $\mathrm{pH}$ and water content as well as that between $\mathrm{pH}$ and reaction temperature also had significantly effects on TAG purity (Figures 4 and 5). From the response surfaces, it indicated that the optimal $\mathrm{pH}$ value of the buffer solution was about 5.5 for lower glycerides hydrolysis and the lower or higher $\mathrm{pH}$ decreased the TAG purity. 
Figure 3. Response surface plot (a) and its contour plot (b) of the TAG purity; temperature $v s$. water content with a constant level of $\mathrm{pH}(\mathrm{pH}=5)$.

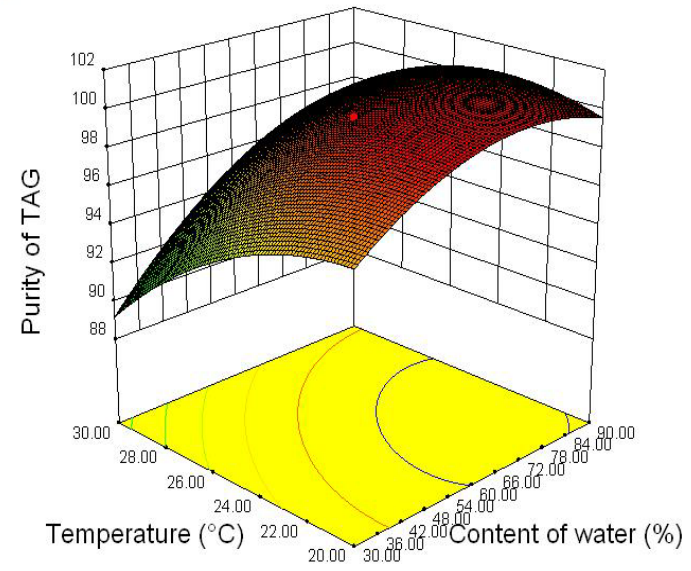

(a)

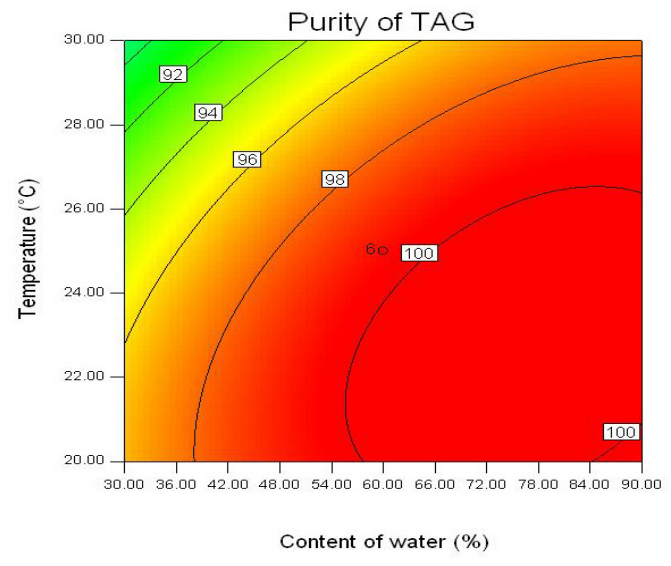

(b)

Figure 4. Response surface plot (a) and its contour plot (b) of the TAG purity; pH vs. water content with a constant level of temperature $\left(20^{\circ} \mathrm{C}\right)$.

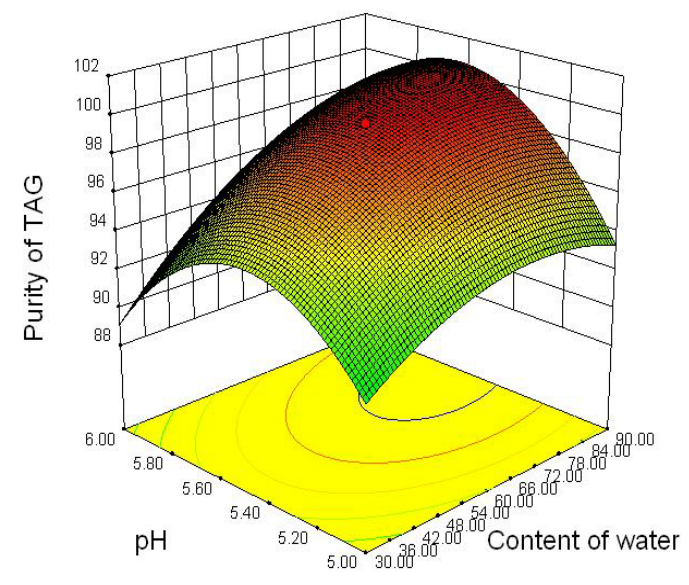

(a)

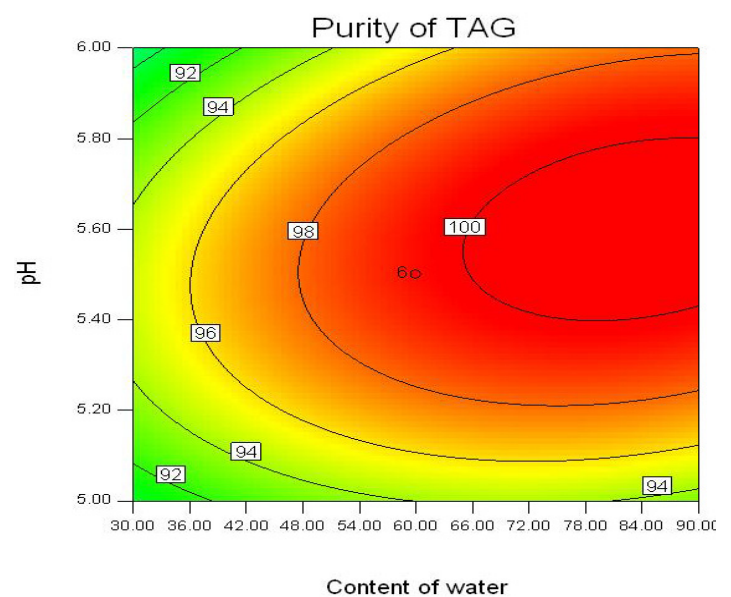

(b)

Figure 5. Response surface plot (a) and its contour plot (b) of the TAG purity; temperature vs. $\mathrm{pH}$ with a constant level of water content $(60 \%)$.

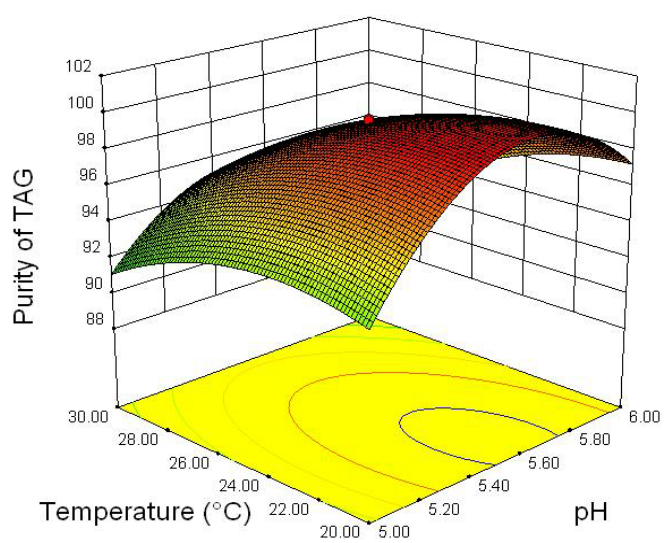

(a)

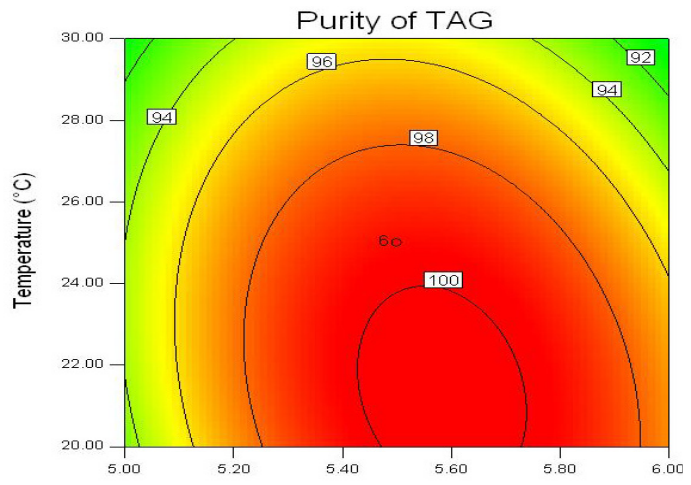

$\mathrm{pH}$

(b) 


\subsubsection{Optimization of Enzymatic Hydrolysis Parameters for TAG Purity}

According to the mathematical model, the optimal levels of the three factors were: water content $66.4 \%, \mathrm{pH} 5.7$ and reaction temperature $19.6{ }^{\circ} \mathrm{C}$, the maximal TAG purity was $100 \%$. The optimal values obtained from response surface plots were consistent with those obtained from the optimized mathematical equation. The experiment was performed under above optimized conditions to verify the predicted results. After $1 \mathrm{~h}$ of hydrolysis, there were only $0.3 \%$ of lower glycerides remained in the reaction mixture and the actual observed TAG purity reached to $99.7 \%$. The results indicated that experimental values of TAG purity had a good agreement with the predicted value.

\subsection{Purification of TAG by Molecular Distillation}

The reaction mixtures were purified using a short path falling film distillation apparatus. The acylglycerol profile and fatty acid composition of purified TAG are shown in Table 3. When the reaction mixture was purified by molecular distillation, the FA was effectively removed, and the most of TAG was successfully collected from the residual fractions because of relatively larger molecular weight of TAG. The final TAG product, which is CLA-enriched TAG, was composed of $99.8 \%$ TAG and $0.2 \%$ DAG. The total yield of CLA-enriched TAG was 38.1\%. In terms of fatty acid composition, the product did not result in significant changes in fatty acid composition of origin and final total CLA, and the content of t10, c12-CLA small increased and c9, t11-CLA decreased than origin. Previous study has reported that the NOVO 435 lipase selective esterified t10, c12-CLA faster than c9, t11-CLA [17]. The CLA content in the final TAG products was $80.20 \%$. The PV of final product was $0.34 \pm 0.04 \mathrm{meq} / \mathrm{kg}$, and the FFA was not found.

Table 3. Acylglycerol profile, fatty acid composition of extremely pure CLA-enriched TAG.

\begin{tabular}{ccc}
\hline & CLA & CLA-enriched TAG \\
\hline Acylglycerol Profile (\%) & & \\
TAG & 0 & 99.8 \\
DAG & 0 & 0.2 \\
MAG & 0 & 0 \\
FA & 100 & 0 \\
Fatty Acid Compositions (\%) & & \\
C16:0 & 4.74 & 4.95 \\
C18:0 & 2.22 & 2.32 \\
C18:1 & 11.47 & 11.56 \\
C18:2 & 0.95 & 0.97 \\
Total CLA & 80.62 & 80.22 \\
c9,t11-CLA & 33.95 & 31.78 \\
t10,c12-CLA & 43.59 & 44.92 \\
Other CLA & 3.08 & 3.52 \\
\hline
\end{tabular}




\section{Experimental}

\subsection{Materials}

Novozym 435 (Candida antarctica B lipase immobilized on a macroporous resin) was purchased from Novozymes (Bagsvaerd, Denmark). The lipase SMG1 (60 U/mL free liquid lipase, lipase activity was determined according to Wang et al. [16]) was produced in lab as our previous report [16]. CLA was purchased from Aohai Biotech Company (Qingdao, China). CLA fatty acid compositions were 4.74\% C16:0, 2.22\% C18:0, 11.4\% C18:1, 0.95\% C18:2, 80.62\% CLA. Chromatographic grade isopropanol, $n$-hexane, the standards of 1(3)-monooleoyl-rac-glycerol (CAS no. 111-03-5), 1,3-dioleoylglycerol (CAS no. 2465-32-9), 1,2-dioleoylglycerol (CAS no. 2442-61-7) and trioleoylglycerol (CAS no. 122-32-7) for HPLC analysis reference and 37 FA methyl esters (CAS no.113 47885-U) for GC analysis reference were acquired from Sigma Aldrich (St. Louis, MO, USA).

\subsection{Preparation of CLA Glycerides}

CLA-enriched triacylglycerol (TAG) were produced by direct esterification of glycerol and CLA using an immobilized lipase from Candida antarctica under vacuum according to the condition reported by Hong et al. [18] Reactions were performed in a $2 \mathrm{~L}$ water-jacketed glass vessel containing glycerol (100 g, $1.08 \mathrm{~mol})$ and CLA (900 g, $3.21 \mathrm{~mol})$. The immobilized lipase (10 g, 1\% of the total weight of substrates) was then added to the mixture. The reaction was initiated with stirring at $600 \mathrm{rpm}, 0.1 \mathrm{kPa}$ and $60{ }^{\circ} \mathrm{C}$. After $6 \mathrm{~h}$ of esterification, the reaction mixture was separated by centrifugation at $6,000 \times g$ for $10 \mathrm{~min}$. The upper mixture of glycerides and fatty acids were obtained.

\subsection{Experimental Design}

The response surface methodology (RSM) was performed to optimize the condition of variables for the hydrolysis of lower glycerides using a central composite rotatable design (CCRD). The water content $\left(X_{1}\right), \mathrm{pH}$ value $\left(X_{2}\right)$, and reaction temperature $\left(X_{3}\right)$ were identified as the major factors. A set of 20 experiments were performed with the first 14 trials organized in a functional factorial design and with the later 15-20 trials relating to replication of the central points. The purity of TAG was taken as the response and the design matrix is shown in Table 1. The quadratic equation (Equation 2) for predicting the variables is as follows:

$$
Y=\beta_{0}+\sum \beta_{i} X_{i}+\sum \beta_{i i} X_{i}^{2}+\sum \beta_{i j} X_{i} X_{j}
$$

where $Y$ is predicted response, $\beta_{0}$ is a constant, $\beta_{\mathrm{i}}, \beta_{\mathrm{ii}}$ and $\beta_{\mathrm{ij}}$ are linear, squared and cross-product coefficient, respectively.

The statistical software Design Expert 8.0 was used to analyze the results. By keeping one variable at its optimal level, three-dimensional plots of two factors versus the TAG purity were drawn. Form the bump of three-dimensional plot, and the optimal conditions of enzymatic hydrolysis of lower glycerides were identified. 


\subsection{Lipase SMG1-Catalyzed Hydrolysis of Lower Glycerides}

The hydrolysis reaction was carried out in a $25 \mathrm{~mL}$ conical flask with stirring at $180 \mathrm{rpm}$. The reaction mixture was composed of esterification product, lipase solution and different amount of distilled water. The reaction conditions of water content $(30 \%$ and $90 \%, \mathrm{w} / \mathrm{w}$, with respect to oil), $\mathrm{pH}$ value (5.0 and 6.0) and reaction temperature $\left(20\right.$ and $\left.30{ }^{\circ} \mathrm{C}\right)$ were varied to investigate their effects on the degree of hydrolysis of lower glycerides (referring to monoacylglycerol and diacylglycerol). CLA could be oxidized for longer reaction time, and the partial glyceride would not be hydrolyzed completely for shorter reaction time. Therefore, reaction time was fixed to 1 h. Aliquots $(20 \mu \mathrm{L})$ of the reaction mixture were periodically withdrawn from the reactions and then were mixed with $1 \mathrm{~mL}$ of $n$-hexane/isopropanol $(15: 1, \mathrm{v} / \mathrm{v})$, after centrifugation at $10,000 \times g$ for $2 \mathrm{~min}$, the supernatant liquid was drawn for HPLC analysis.

\subsection{Purification of the TAG by Molecular Distillation}

The non-polar layer (TAG, FA, and/or MAG, DAG) of the final reaction mixture from the hydrolysis process was collected after centrifugation at $2,770 \times g$ for $10 \mathrm{~min}$. In order to obtain pure CLA-enrich TAG, the FFA in the mixture was removed by a molecular distillation (MD-S80 short path falling film distiller, Guangzhou Hanwei Co., Ltd., Guangzhou, China). An evaporating temperature of $150{ }^{\circ} \mathrm{C}$, a feeding temperature of $60{ }^{\circ} \mathrm{C}$, respectively, a feed flow rate of $2.7 \mathrm{~g} / \mathrm{min}$, a condenser temperature of $25^{\circ} \mathrm{C}$, a pressure of $8.1 \mathrm{~Pa}$ and a scraper speed of $250 \mathrm{rpm}$ were used for the removal process. The residues with TAG and/or DAG, MAG were collected for HPLC analysis.

\subsection{HPLC Analysis of the Products}

The content of TAG and FFA in the ersterification products, hydrolytic products and the residue oil after the molecular distillation was analyzed by a Waters 2695 HPLC with a parallax refractive index detector on a Phenomenex Luna silica column (Phenomenex Corporation, Torrance, CA, USA, $250 \mathrm{~mm} \times 4.6 \mathrm{~mm}$ i.d., $5 \mu \mathrm{m}$ particle size). The mobile phase was a mixture of $n$-hexane and isopropanol $(15: 1 \mathrm{v} / \mathrm{v})$ with a flow rate of $1.0 \mathrm{~mL} / \mathrm{min}$. Peaks in HPLC were identified by comparison of their retention times with reference standards. Peak-areas percentages were calculated using Waters 2695 integration software. The product mixture of esterification reaction contains glycerol, FFA, MAG, DAG and TAG. Glycerol and FFA can be removed easily by molecular distillation. And the DAG and MAG cause the difficulty for purifying TAG, because of the small vapor pressure difference between DAG and TAG. It is necessary to reduce the content of DAG and MAG. Thus, TAG purity was defined as Equation 3.

$$
\text { TAG purity }(\%)=\frac{T A G(\%)}{T A G(\%)+D A G(\%)+M A G(\%)} \times 100
$$

\subsection{Analysis of Fatty Acid Compositions of TAGs}

The TAG fraction in the esterification products was separated by a thin-layer chromatography (TLC) plate $(100 \times 200 \mathrm{~mm})$ coated with silica gel and was developed in a TLC tank using petroleum ether/ethyl 
ether/acetic acid 80/20/1 (v/v/v). The bands were visualized with $0.2 \%$ 2,7-dichlorofluorescein in methanol under ultraviolet light and the TAG band was scraped off for the analysis of FA composition.

The TAGs were transmethylated according to ISO 5509:2000(E) [19]. Samples were added to a round-bottom flask for methyl transesterification and then were separated on a FFAP column (PERMABOND-FFFAP DF-0.25, $25 \mathrm{~m} \times 0.25 \mathrm{~mm}$ i.d., Macherey-Nagel, Düren, Germany) by an Agilent 7890 GC (Agilent Tech, Santa Clara, CA, USA) using nitrogen as the carrier gas. A temperature program was used to keep the samples in a column oven at $150{ }^{\circ} \mathrm{C}$ for $2 \mathrm{~min}$. The temperature was increased to $230{ }^{\circ} \mathrm{C}$ at $10^{\circ} \mathrm{C} / \mathrm{min}$ and held for $8 \mathrm{~min}$ for a total run time of $18 \mathrm{~min}$. The split ratio was 50:1. The injector and the flame ionization detector temperatures were set at 250 and $300^{\circ} \mathrm{C}$, respectively.

\subsection{Other Analyses}

The free fatty acid (FFA) of the test oils was determined with the alkali titration method [20]. The peroxide value (PV) was determined spectrophotometrically by the International Dairy Federation (IDF) method [21].

\subsection{Statistics}

All analytical determinations were carried out in triplicate. The results are reported as the means \pm standard deviations (SD) of these measurements.

\section{Conclusions}

In summary, the designed synthesis method providea useful process for the production of extremely pure CLA-enriched TAG. Due to the thermal instability of CLA, high temperature molecular distillation $\left(220-250^{\circ} \mathrm{C}\right)$ cannot be applied to separate lower glycerides from TAG, which will still exist in the final products and result in the low TAG purity. The presented method provides an alternative process to separate the lower glycerides by lipase SMG1-catalyzed hydrolysis.

RSM was successfully adopted to model and optimize the hydrolysis of lower glycerides and main effects and interactions between the three reaction parameters (water content, $\mathrm{pH}$ and reaction temperature) were fully elucidated. The optimized conditions by lipase SMG1-catalyzed hydrolysis of lower glycerides were as following: water content of $66.4 \%$ (w/w, with respect to oil mass), $\mathrm{pH}$ at 5.7 and $1 \mathrm{~h}$ of reaction time at $19.6{ }^{\circ} \mathrm{C}$. Based on the optimal conditions, only $0.3 \%$ of lower glycerides remained in the reaction mixture and the purity of CLA-enriched TAG reached to $99.7 \%$. A lower temperature molecular distillation $\left(150^{\circ} \mathrm{C}\right)$ was employed to separate the FFA from TAG and the final CLA-enriched TAG product yielded $99.8 \%$ of TAG. By applying this method, extremely pure CLA-enriched TAG can be easily obtained at a purity of over $98 \%$ for use in studies of the CLA metabolism in animals and humans.

\section{Acknowledgments}

This work was made possible with funding by Program for New Century Excellent Talents in University (No. NCET-11-0160), and National Science Funds for the Excellent Youth Scholars (31222043) and the China Postdoctoral Science Found (Grant No. 2012M511816). 


\section{Conflict of Interest}

The authors have declared no conflict of interest.

\section{References}

1. Zhong, X.F.; Luo, T.; Huang, G.D.; Deng, Z.Y.; Lei, L. Equimolar mixture of c9,t11 and t9,t11 CLA inhibits the growth and induces apoptosis in Caco-2 cells. Eur. J. Lipid. Sci. Technol. 2012, 114, 479-485.

2. Whigham, L.D.; Cook, M.E.; Atkinson, R.L. Conjugated linoleic acid: Implications for human health. Pharmacol. Res. 2000, 42, 503-510.

3. Belury, M.A. Inhibition of carcinogenesis by conjugated linoleic acid: Potential mechanisms of action. J. Nutr. 2002, 132, 2995-2998.

4. Oraldi, M.; Maggiora, M.; Paiuzzi, E.; Canuto, R.A.; Muzio, G. CLA Reduces Inflammatory Mediators from A427 Human Lung Cancer Cells and A427 Conditioned Medium Promotes Differentiation of C2C12 Murine Muscle Cells. Lipids 2013, 48, 29-38.

5. Tricon, S.; Burdge, G.C.; Kew, S.; Banerjee, T.; Russell, J.J.; Jones, E.L.; Grimble, R.F.; Williams, C.M.; Yagoob, P.; Calder, PC. Opposing effects of cis-9, trans-11 and trans-10, cis-12 conjugated linoleic acid on blood lipids in healthy humans. Am. J. Clin. Nutr. 2004, 80, 614-620.

6. Miner, J.L.; Cederberg, C.A.; Nielsen, M.K.; Chen, X.; Baile, C.A. Conjugated Linoleic Acid (CLA), Body Fat, and Apoptosis. Obes. Res. 2012, 9, 129-134.

7. Thom, E.; Wadstein, J.; Gudmundsen, O. Conjugated linoleic acid reduces body fat in healthy exercising humans. J. Int. Med. Res. 2001, 29, 392-396.

8. Terpstra, A.; Javadi, M.; Beynen, A.; Kocsis, S.; Lankhorst, A.E.; Lemmens, A.G.; Mohede, I.C. Dietary conjugated linoleic acids as free fatty acids and triacylglycerols similarly affect body composition and energy balance in mice. J. Nutr. 2003, 133, 3181-3186.

9. Fernie, C.E.; Dupont, I.E.; Scruel, O.; Carpentier, Y.A.; Sebedio, J.L.; Scrimgeour, C.M. Relative absorption of conjugated linoleic acid as triacylglycerol, free fatty acid and ethyl ester in a functional food matrix. Eur. J. Lipid. Sci. Tech. 2004, 106, 347-354.

10. Stewart, J.E.; Feinle-Bisset, C.; Keast, R.S. Fatty acid detection during food consumption and digestion: Associations with ingestive behavior and obesity. Prog. Lipid Res. 2011, 50, 225-233.

11. Medina, A.R.; Cerdán, L.E.; Giménez, A.G.; Páez, B.C.; González, M.J.I.; Grima, E.M. Lipase-catalyed esterification of glycerol and polyunsaturated fatty acids from fish and microalgae oils. J. Biotechnol. 1999, 70, 379-391.

12. Torres, C.F.; Garcia, H.S.; Ries, J.J.; Hill, C.G., Jr. Esterification of glycerol with conjugated linoleic acid and long-chain fatty acids from fish oil. J. Am. Oil Chem. Soc. 2001, 78, 1093-1098.

13. Busch, S.; Horlacher, P.; Both, S.; Westfechtel, A.; Schörken, U. Green synthesis routes toward triglycerides of conjugated linoleic acid. Eur. J. Lipid. Sci. Tech. 2011, 113, 92-99.

14. Wang, Y.H.; Jing, C.F.; Yang, B.; Mainda, G.; Dong, M.L.; Xu, A.L. Production of a new sea anemone neurotoxin by recombinant Escherichia coli: Optimization of culture conditions using response surface methodology. Process. Biochem. 2005, 40, 2721-2728. 
15. Wang, Y.; Zhao, M.M.; Ou, S.Y.; Xie, L.Y.; Tang S.Z. Preparation of a diacylglycerol-enriched soybean oil by phosphalipase A1 catalyzed hydrolysis. J. Mol. Catal. B Enzy. 2009, 56, 165-172.

16. Wang, W.F.; Li, T.; Qin, X.L.; Ning, Z.X.; Yang, B.; Wang, Y.H. Production of lipase SMG1 and its application in synthesizing diacylglyecrol. J. Mol. Catal. B Enzy. 2012, 77, 87-91.

17. Wang, Y.H.; Li, X.F.; Liang, Y.C.; Yang, B.; Zhang, S.J. Enzymatic fractionation of conjugated linoleic acid isomers by selective esterification. J. Mol. Catal. B Enzy. 2007, 46, 20-25.

18. Hong, S.I.; Kim, Y.; Yoon, S.W.; Cho, S.Y.; Kim, I.H. Synthesis of CLA-enriched TAG byCandida antarcticalipase under vacuum. Eur. J. Lipid Sci. Tech. 2012, 114, 1044-1051.

19. European Committee for Standardization. Animal and vegetable fats and oils-Gas chromatography of fatty acid methyl esters - Part 2: Preparation of methyl esters of fatty acids. 2011, ISO Method 12966-2.

20. Official Methods and Recommended Practices of the American Oil Chemists' Society, 4th ed., AOCS Press: Champaign, IL, USA, 1993; Methods Ca-5a.

21. Shantha, N.C.; Decker, E.A. Rapid, sensitive, iron-based spectrophotometric methods for detecmination of peroxide values of food lipids. J. AOAC Int. 1994, 77, 421-424.

Sample Availability: Samples of the compounds CLA-enriched TAG is available from the authors.

(C) 2013 by the authors; licensee MDPI, Basel, Switzerland. This article is an open access article distributed under the terms and conditions of the Creative Commons Attribution license (http://creativecommons.org/licenses/by/3.0/). 